\title{
Fast Hierarchical Search Method for Multi-view Video Coding
}

\author{
Yoon Hyo-Sun ${ }^{\dagger} \cdot$ Kim Mi-Young ${ }^{*+}$
}

\begin{abstract}
Motion estimation (ME) that limits the performance of image quality and encoding speed has been developed to reduce temporal redundancy in video sequences and plays an important role in digital video compression. But it is computational demanding part of the encoder. Multi-view video is obtained by capturing one three-dimensional scene with many cameras at different positions. ME for Multi-view video requires high computational complexity. To reduce computational complexity and maintain the image quality, a fast motion estimation method is proposed in this paper. The proposed method uses a hierarchical search strategy. This strategy method consists of modified diamond search patten, multi gird diamond search pattern, and raster search pattern. These search patterns place search points symmetrically and evenly that can cover the overall search area not to fall into the local minimum or exploits the characteristics of the distribution of motion vectors to place the search points. Experiment results show that the speedup improvement of the proposed method over TZ search method (JMVC) can be up to $1.2 \sim 3$ times faster while maintaining similar video quality and bit rates.
\end{abstract}

Keywords : Motion Estimation, Video Compression, Motion Vector, Multi-view Video, Multi-view Video Coding, JMVC

\section{다시점 비디오 부호화를 위한 고속 계층적 탐색 기법}

\author{
윤 효 순 + 김 미 영 ${ }^{++}$
}

\begin{abstract}
요 약
영상 화질과 인코더의 속도에 영향을 주는 움직임 추정은 동영상 내에 존재하는 중복된 데이터를 제거하기 때문에 동영상 압축에서 중요한 역할을 하지만 높은 계산 복잡도를 요구한다. 다시점 비디오는 하나의 3차원 장면을 여러 시점에서 다수의 카메라로 촬영한 동영상으로 다시점 비디오를 위한 움직임 추정은 카메라 수에 비례하여 많은 계산량을 필요로 한다. 본 논문에서는 다시점 비디오 부호화를 위한 움직임 추정의 계산량을 줄이면서 영상 화질을 유지하는 고속 움직임 추정 기법을 제안한다. 제안한 기법은 계층적인 탐색 기법으로 수정된 다이아몬드 탐색 패턴, 다중 다이아몬드 탐색 패턴, 그리고 래스터 탐색 패턴으로 구성된다. 이 탐색 패턴들은 국부적 최소화 문제를 해결하기 위하여 탐색 영역 내에 탐색 점들을 규칙적, 대칭적으로 배치하거나 움직임 벡터의 분포 특성을 이용하여 탐색 점들을 배치한다. 제안한 기법의 성능은 JMVC의 고속 움직임 추정 기법인 TZ 탐색 기법의 성능과 비교한 경우, 영상 화질과 비트량을 비슷하지만 계산량을 줄임으로서 움직임 추정 속도를 약 $1.2 \sim 3$ 배 향상시킨다.
\end{abstract}

키워드 : 움직임추정, 비디오 압축, 움직임 벡터, 다시점 비디오, 다시점 비디오 부호화, JMVC

\section{1. 서 론}

최근 데이터 압축 기술과 데이터 전송 속도 향상 그리고 통신 기술 발달로 다양한 멀티미디어 콘텐츠를 사용자에게 제공할 수 있게 되었다. 그리고 자유 시점 $\mathrm{TV}$ (free viewpoint television), 3차원 TV와 같은 멀티미디어 시스템

\footnotetext{
※ 이 논문은 2012년도 정부(교육과학기술부)의 재원으로 한국연구재단의 기초연구사업을 지원을 받아 수행된 연구임(No.2012-0007893).

† 준 회 원 전남대학교 전산학과 이학박사

†정 회 원:전남도립대학교 보건의료과 교수

논문접수: 2012 년 11 월 14 일

수 정 일 : 1 차 2013년 4월 29일

심사완료 : 2013년 4월 29일

* Corresponding Author:Kim Mi-Young(kimmee@dorip.ac.kr)
}

의 발달로 인하여 실감 미디어 콘텐츠에 대한 수요가 급증 하고 있다[1]. 이에 따라 다시점 비디오는 3차원 영상에 대 한 다양한 사용자의 요구를 충족시킬 수 있는 대안으로 주 목 받고 있다.

다시점 비디오는 여러 개의 카메라로 동시에 하나의 3 차 원 장면을 촬영한 동영상의 집합으로 사용자에게 임의 시점 을 제공하며 여러 시점의 영상을 합성하여 보다 넓은 화면 을 제공할 수 있지만 카메라의 수에 비례하여 데이터의 양 이 늘어나기 때문에 다시점 비디오를 효율적으로 부호화하 는 기술을 요구한다[2].

다시점 비디오는 인접한 시점의 영상들 사이에는 화면 간 중복성이 존재하고 같은 시점 영상들 사이에는 시간적 중복 
성이 존재한다. 그러므로 다시점 비디오 부호화는 영상들 사이에 존재하는 시간적 중복성과 시점 간 중복성을 제거함 으로써 데이터를 압축한다. 특히 가장 많은 데이터 중복성 을 가지고 있는 시간적 중복성은 움직임 추정을 수행하여 제거한다.

영상 화질과 인코더의 속도에 영향을 주는 움직임 추정은 동영상 압축에서 중요한 역할을 하지만 전체 인코더에서 많 은 계산량을 요구한다. 움직임 추정에 소요되는 계산량을 줄이기 위하여 다음과 같은 고속 움직임 추정 기법들이 제 안되었다. 대표적인 고속 움직임 추정 기법에는 3단계 탐색 (Three Step Search:TSS)[3], 새로운 3단계 탐색(New Three Step Search:NTSS)[4], 2차원 로그형 탐색(2 Dimension LOGarithmic search:2DLOG)[5], 4단계 탐색 (Four Step Search:4SS)[6], 다이아몬드 탐색(Diamond Search:DS)[7][8], 2단계 탐색(2 Step Search:2SS)[9][10], 움 직임 벡터를 추정하는 움직임 벡터 필드 적응적 탐색 기법 (MVFAST)[11], 육단계 탐색 기법(Hexagonal Search:HS) [12] 그리고 예측된 움직임 벡터 필드 적응적 탐색기법 (PMVFAST)[13]등이 있다.

고속 움직임 추정 기법[3-13]들은 상대적으로 움직임이 작은 영상이나 영상 크기가 작은 경우에 움직임 벡터 추정 을 잘 수행하지만 영상의 움직임이 크거나 영상의 크기가 큰 경우에 움직임 추정 시 국부적 최소화 문제에 빠지게 되 므로 정확한 움직임 벡터를 추정할 수 없으므로 영상 화질 저하를 가져온다. 영상의 움직임이 크거나 영상 크기가 상 대적으로 큰 영상에서 움직임 벡터 추정을 잘 수행할 수 있 는 비대칭 다중 육각형 탐색 기법[14]을 사용하여 화질 저하 를 개선하였다. 그러나 블록 움직임이 수직으로 크거나 블 록 움직임이 크면서 규칙적인 영상에서 비대칭 다중 육각형 탐색 기법은 탐색 영역 내에 배치하는데 있어서 비대칭적, 불규칙적으로 배치해 국부적 최소화에 빠질 수 있다.

위에서 나열한 기법[3-14]들은 일반적으로 단일 시점 영 상에서 사용되는 움직임 추정 기법이다. 다시점 비디오를 압축하기 위하여 JMVC에서 사용되는 고속 움직임 추정 기법은 $\mathrm{TZ}$ 탐색 기법이다[15]. TZ 탐색 기법은 초기에 탐 색 영역 전역에 탐색 점들을 배치해 움직임이 작은 블록 에 대해 불필요한 탐색 점들을 검사함으로써 많은 계산량 을 요구한다.

본 논문에서는 다시점 비디오 부호화를 위한 움직임 추정 의 계산량을 줄이면서 영상 화질과 발생 비트량을 유지하는 고속 움직임 추정 기법을 제안한다. 제안한 움직임 추정 기 법은 계층적인 탐색 기법으로 수정된 다이아몬드 탐색 패턴 [14], 다중 다이아몬드 탐색 패턴, 그리고 래스터 탐색 패턴 으로 구성된다. 수정된 다이아몬드 탐색 패턴은 본 논문의 연구진이 기존에 제안한 기법으로 움직임이 작은 블록에서 좋은 결과를 보였다. 본 논문에서 제안된 움직임 추정 기법 은 국부적 최소화 문제를 해결하기 위하여 탐색 영역 내에 탐색 점들을 규칙적, 대칭적으로 배치하거나 움직임 벡터 분포의 특성을 이용하여 탐색 점들을 배치하였다. 그리고
블록 움직임의 크기에 따라 적절한 탐색 패턴을 사용함으로 써 움직임 추정 계산량을 줄였다.

본 논문의 구성은 다음과 같다. 2 장에서는 $\mathrm{JMVC}$ 의 고속 움직임 추정 기법인 $\mathrm{TZ}$ 탐색 기법에 대하여 설명하고, 3장 에서는 본 논문에서 제안한 움직임 추정 기법을 기술한다. 그리고 4장에서는 $\mathrm{TZ}$ 탐색 기법과 성능을 비교한 후, 마지 막으로 5장에서는 결론을 맺는다.

\section{TZ 탐색 기법}

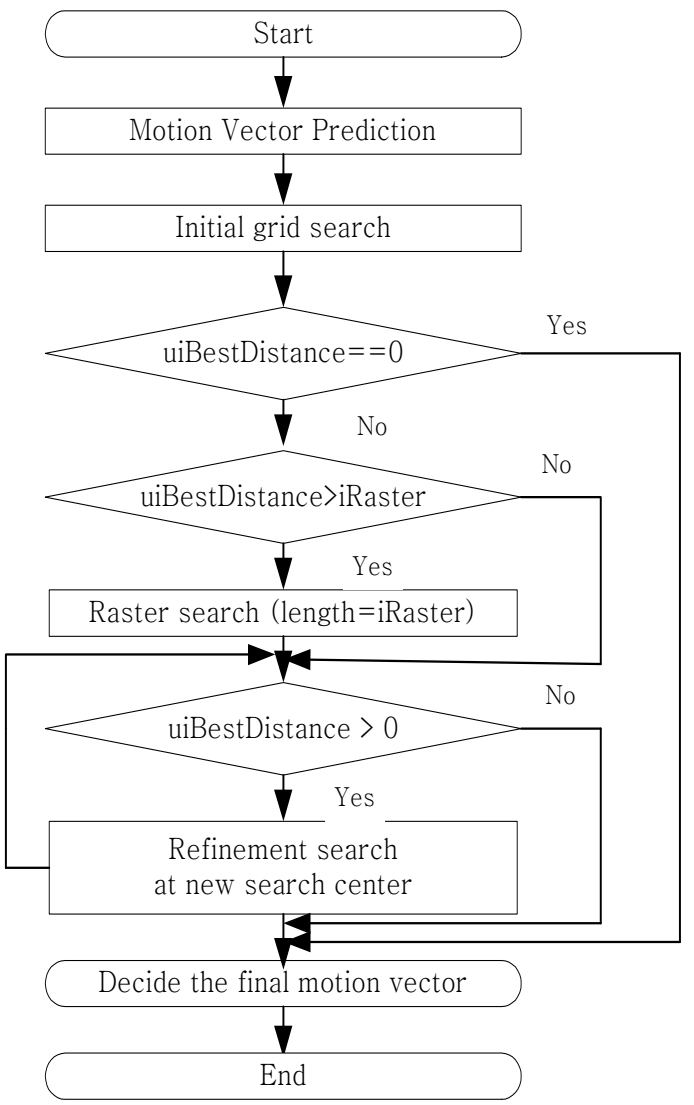

Fig. 1. Flowchart of TZ Algorithm

$\mathrm{JMVC}$ 의 고속 움직임 추정 기법은 $\mathrm{TZ}$ 탐색 기법이다. 그 리고 $\mathrm{TZ}$ 탐색 기법의 알고리즘 순서도는 Fig. 1과 같다. $\mathrm{TZ}$ 탐색 기법은 다음과 같은 알고리즘을 수행하여 움직임 벡터를 추정한다.

[단계 1] : 움직임 벡터 예측 (Motion Vector Prediction) 메디안 예측, 상위 모드를 이용한 예측, 이전 화면의 대응 블록을 이용한 예측, 이웃한 참조 화면을 이용한 예측들을 사용하여 초기 탐색 시작점을 결정한다.

[단계 2] : 초기 그리드 탐색 (Initial Grid search)

초기 탐색 시작점을 탐색의 원점으로 초기 그리드 탐색 패턴을 사용한다. 초기 그리드 탐색 패턴 stride length의 범 위는 $1,2,4,8,16,32,64$ 이다. Fig. $2 \mathrm{~A}$ 는 stride length가 


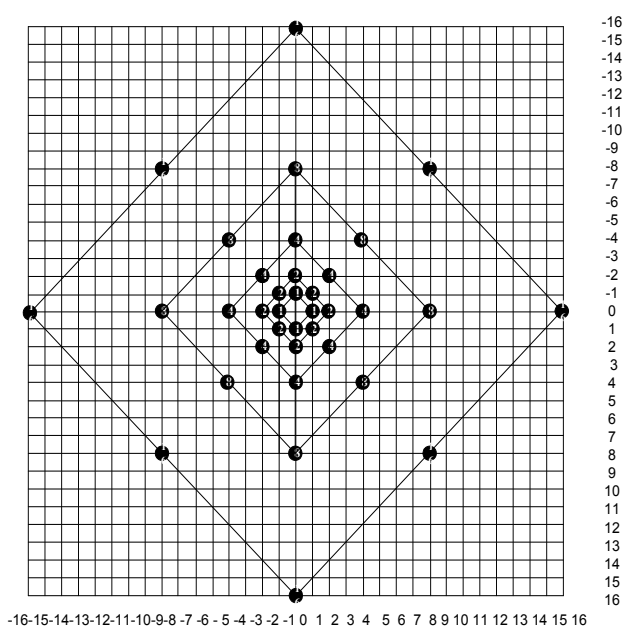

(A) Initial grid search pattern (stride length 16)

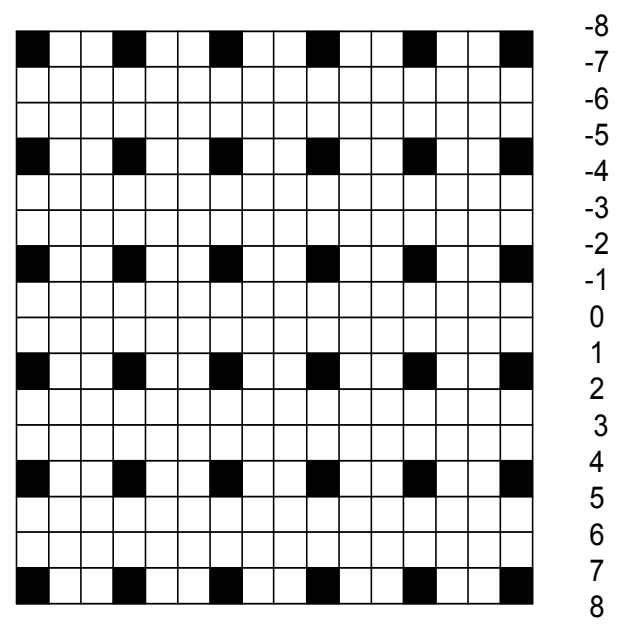

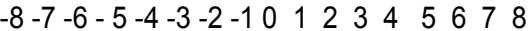

(B) Raster search pattern (raster length $=3$ )

Fig. 2. Search patterns of TZ Algorithm

16 인 초기 그리드 탐색 패턴이다. Fig. $2 \mathrm{~A}$ 와 같은 방법으로 탐색 범위에 탐색 점들을 배치한다. 탐색 점들 중 최소 비 용함수 값을 가지는 점이 [단계 2]의 최적 탐색점이다.

[단계 3] : 초기 탐색 시작점과 [단계 2]의 최적 탐색점 사이의 거리(uiBestDistance)를 구한다.

uiBestDistance가 0이면 초기 탐색 시작점을 움직임 벡 터로 추정하고 움직임 추정을 마친다. 만약 uiBestDistance 가 래스터 탐색의 iRaster (stride length) 보다 크면 [단계 4]를 수행하고 그렇지 않으면 [단계 5]를 수행한다.

[단계 4] : 래스터 탐색 (Raster search)

Fig. 2B는 raster length가 3인 래스터 탐색 패턴이다. Fig. $2 \mathrm{~B}$ 와 같은 방법으로 탐색 영역 내에 탐색 점들을 배치 한다. 탐색 점들 중 최소 비용 함수 값을 가지는 점이 [단계 4]의 최적 탐색점이다.

[단계 5] : 정교한 탐색 (Refinement search)

탐색 시작점을 변경한 후 [단계 2]의 초기 그리드 탐색을 수행한다. 탐색 점들 중 최소 비용함수 값을 가지는 점이 [단계 5]의 최적 탐색점이다. 그리고 변경된 탐색 시작점과 [단계 5]의 최적 탐색점 사이의 거리(uiBestDistance)를 구 한다.

uiBestDistance가 0이면 [단계5]의 최적 탐색점을 움직임 벡터로 추정하고 움직임 추정을 마친다. 그렇지 않으면 [단 계5]를 반복 수행한다.

\section{3. 제안한 움직임 추정 기법 - 고속 계층적 탐색 기법}

$\mathrm{TZ}$ 탐색 기법에서 사용하는 초기 그리드 탐색은 탐색 영 역 전역에 탐색 점들을 배치한 후 최적의 탐색 점을 찾고 래스터 탐색 역시 탐색 영역 전역에 탐색 점들을 수직, 수 평 방향으로 배치하여 최적의 탐색 점을 찾는다. 이것은 초
기 그리드 탐색에서 iRaster(래스터 탐색의 탐색 길이:3) 보 다 큰 탐색 영역에 있는 탐색 점들을 검사할 필요가 없다는 것을 의미한다. 즉, 탐색 시작점과 최적의 탐색점 사이의 거 리(uiBestDistance)가 iRaster보다 큰 경우, 래스터 탐색을 수행할 때 초기 그리드 탐색 점들이 배치된 영역에 탐색 점 들을 배치하여 검사하기 때문이다. 그래서 제안한 기법에서 는 Fig. 3(a)의 다중 다이아몬드 탐색 패턴을 이용하여 iRaster+1인 탐색 영역 내에만 탐색 점들을 배치하여 중복 된 탐색 점들의 수를 줄임으로서 계산량을 줄였다.

그리고 $\mathrm{TZ}$ 탐색 기법의 정교한 탐색은 uiBestDistance가 0이 될 때까지 초기 그리드 탐색 패턴을 반복 수행하는데, 이 때 불필요한 탐색 점들을 배치하고 검사한다. 이러한 문 제점을 해결하기위하여 제안한 고속 움직임 추정 기법은 Fig. $3 \mathrm{~B}$ 와 같이 탐색 영역의 원점을 중심으로 반경 2화소 이내에 움직임 벡터가 분포할 확률이 약 $56 \%$ (블록의 움직 임이 큰 영상) $98 \%$ (블록의 움직임이 작은 영상)[7,16]이라 는 사실을 이용한 수정된 다이아몬드 탐색 패턴을 사용하였 다. 수정된 다이아몬드 탐색 패턴은 탐색 영역의 중심에 있 는 모든 탐색 점들이 블록정합의 대상이 되도록 추가 탐색 점들을 적절히 배치하였다.

제안한 움직임 추정 기법은 블록 움직임의 크기에 따라 적응적으로 탐색 패턴을 사용함으로써 움직임 추정의 계 산량을 줄였다. 제안한 움직임 추정 기법은 Fig. $3 \mathrm{~A}$ 의 다 중 다이아몬드 탐색 패턴, Fig. $3 \mathrm{~B}$ 의 수정된 다이아몬드 탐색 패턴, 그리고 Fig. $2 \mathrm{~B}$ 의 래스터 탐색 패턴으로 구성 된다. 이 탐색 패턴들은 국부적 최소화 문제를 해결하기 위하여 탐색 영역 내에 탐색 점들을 규칙적, 대칭적으로 배치하거나 움직임 벡터의 분포 특성을 이용하여 탐색 점 들을 배치한다. 제안한 움직임 추정 기법의 알고리즘 순서 도는 Fig. 4와 같고 다음과 같은 알고리즘을 수행하여 움 직임 벡터를 추정한다. 


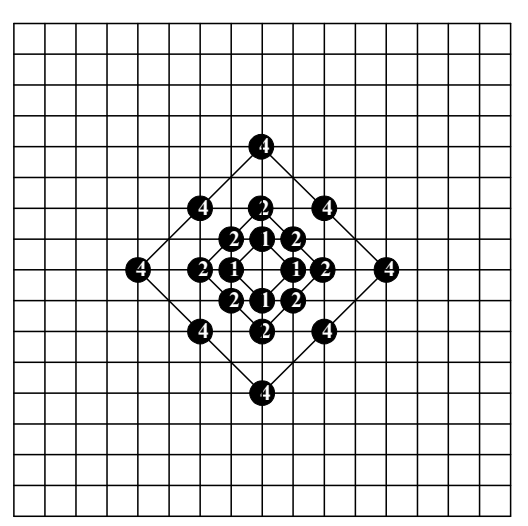

$-8-7-6-5-4-3-2-1001233455678$

(A) Multi-grid Diamond search pattern

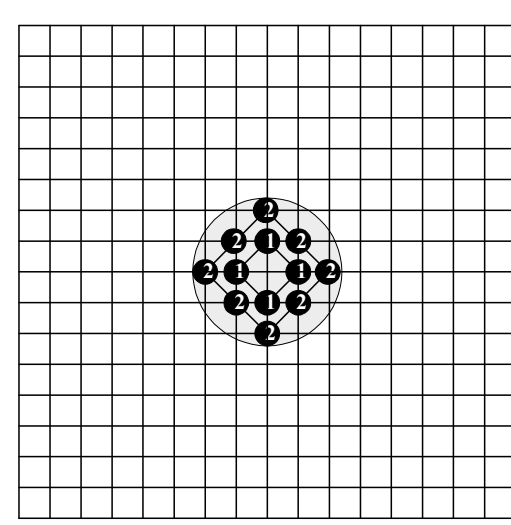

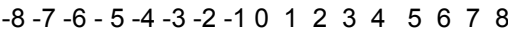

(B) Modified Diamond search pattern

Fig. 3. Search patterns of the proposed motion estimation method

[단계 1] : 움직임 벡터 예측 (Motion Vector Prediction) 메디안 예측, 상위 모드를 이용한 예측, 이전 화면의 대응 블록을 이용한 예측, 이웃한 참조 화면을 이용한 예측들을 사용하여 초기 탐색 시작점을 결정한다.

[단계 2] : 다중 다이아몬드 탐색 (Multi Grid Diamond search)

Fig. $3 \mathrm{~A}$ 와 같은 다중 다이아몬드 탐색 패턴을 이용하여 초 기 탐색 시작점 주위에 탐색 점들을 배치한다. 탐색 점들 중 최소 비용함수 값을 가지는 점이 [단계 2]의 최적 탐색점이다.

[단계 3] :초기 탐색 시작점과 [단계 2]의 최적 탐색점 사 이의 거리(uiBestDistance)를 구한다. uiBestDistance가 0이 면 초기 탐색 시작점을 움직임 벡터로 추정하고 움직임 추 정을 마친다. 만약 uiBestDistance가 래스터 탐색의 iRaster (stride length) 보다 크면 [단계 4]를 수행하고 그렇지 않으 면 [단계 5]를 수행한다.

[단계 4] : 래스터 탐색 (Raster search)

iRaster를 변경한 후, Fig. 2B와 같은 방법으로 탐색 영역 내에 탐색 점들을 배치하여 래스터 탐색을 수행한다. 탐색 점들 중 최소 비용함수 값을 가지는 점을 [단계 4]의 최적 탐색점이라 한다.

[단계 5] : 수정된 다이아몬드 탐색

탐색 시작점을 변경한 후 수정된 다이아몬드 탐색을 수행 한다. 탐색 점들 중 최소 비용함수 값을 가지는 점이 [단계 5]의 최적 탐색점이다. 그리고 변경된 탐색 시작점과 [단계 5]의 최적 탐색점 사이의 거리(uiBestDistance)를 구한다.

uiBestDistance가 0이면 [단계5]의 최적 탐색점 움직임 벡 터로 추정하고 움직임 추정을 마친다. 그렇지 않으면 [단계 5]를 반복 수행한다.

\section{4. 실험 결과}

제안하는 예측 구조의 성능을 확인하기 위하여 제안하는 예측 구조를 JMVM 6.0에서 구현하였다. 실험 영상으로 $640 \times 480$ 크기의 Exit, Ballroom, Race1, Flamenco2와

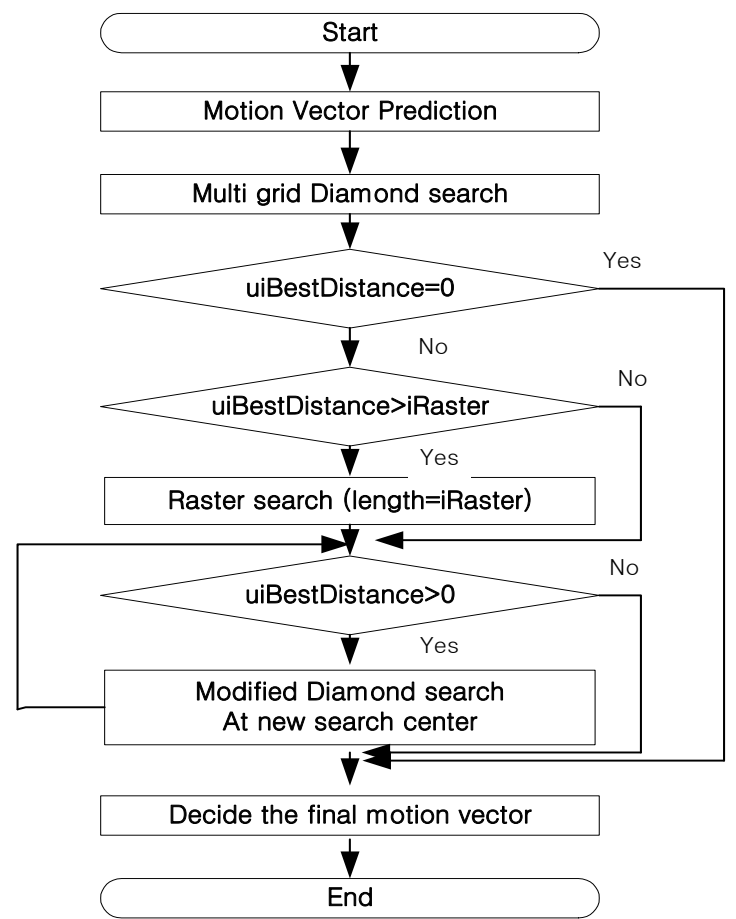

Fig. 4. Flowchart of the proposed motion estimation method

$1024 \times 768$ 크기의 Uli를 사용하였다. Exit, Ballroom, Race1, Uli는 1차원 배열의 영상이고 Flamenco2는 2차원 배열 영상 이다. 실험조건은 Table 1에 나타내었다.

Table 1. Experiment Conditions

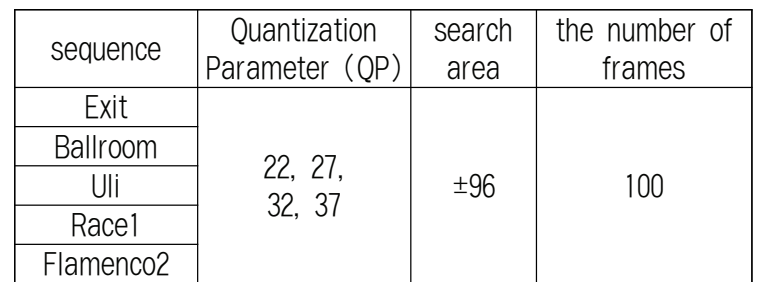


Table 2. Simulation Results : Average PSNR_Y(dB) and Average Bitrates

\begin{tabular}{|c|c|c|c|c|c|c|c|}
\hline \multirow[b]{2}{*}{ Sequence } & \multirow[b]{2}{*}{$\mathrm{QP}$} & \multicolumn{2}{|c|}{ TZHI } & \multicolumn{2}{|c|}{$\mathrm{TZ}$} & \multicolumn{2}{|c|}{ Proposed method } \\
\hline & & $\begin{array}{c}\text { Bitrates } \\
\text { (kbps) }\end{array}$ & PSNR_Y (dB) & $\begin{array}{c}\text { Bitrates } \\
\text { (kbps) }\end{array}$ & PSNR_Y (dB) & $\begin{array}{c}\text { Bitrates } \\
\text { (kbps) }\end{array}$ & PSNR_Y $(\mathrm{dB})$ \\
\hline \multirow{4}{*}{ Exit } & 22 & 797.09 & 39.84 & 794.72 & 39.85 & 812.83 & 39.83 \\
\hline & 27 & 340.29 & 38.28 & 337.60 & 38.03 & 351.83 & 38.27 \\
\hline & 32 & 179.06 & 36.39 & 177.44 & 36.44 & 193.81 & 36.38 \\
\hline & 37 & 107.05 & 34.11 & 105.36 & 34.17 & 117.65 & 34.09 \\
\hline \multirow{4}{*}{ Uli } & 22 & 4154.02 & 38.98 & 4148.45 & 38.99 & 4171.33 & 38.98 \\
\hline & 27 & 2202.02 & 36.96 & 2197.35 & 36.97 & 2215.43 & 36.96 \\
\hline & 32 & 1225.13 & 34.42 & 1215.34 & 34.40 & 1229.97 & 34.43 \\
\hline & 37 & 675.33 & 31.60 & 667.83 & 31.62 & 679.14 & 31.61 \\
\hline \multirow{4}{*}{ Ballroom } & 22 & 1504.70 & 39.05 & 1494.35 & 39.04 & 1520.81 & 39.05 \\
\hline & 27 & 758.73 & 36.80 & 751.27 & 36.82 & 779.62 & 36.80 \\
\hline & 32 & 407.38 & 34.25 & 402.10 & 34.28 & 423.33 & 34.25 \\
\hline & 37 & 230.66 & 31.56 & 226.70 & 31.56 & 242.00 & 31.54 \\
\hline \multirow{4}{*}{ Race1 } & 22 & 1230.89 & 39.90 & 1204.80 & 39.92 & 1250.82 & 39.88 \\
\hline & 27 & 603.72 & 37.24 & 582.93 & 37.30 & 622.14 & 37.06 \\
\hline & 32 & 314.07 & 34.56 & 298.58 & 34.63 & 327.13 & 34.31 \\
\hline & 37 & 187.63 & 31.81 & 174.83 & 31.95 & 198.78 & 31.52 \\
\hline \multirow{4}{*}{ Flamenco2 } & 22 & 1773.05 & 41.25 & 1759.47 & 41.26 & 1791.61 & 41.25 \\
\hline & 27 & 973.98 & 38.39 & 962.37 & 38.42 & 989.82 & 38.40 \\
\hline & 32 & 528.56 & 35.37 & 521.85 & 35.39 & 537.95 & 35.38 \\
\hline & 37 & 284.36 & 32.36 & 278.78 & 32.38 & 291.84 & 32.38 \\
\hline
\end{tabular}

Table 3. the Bjontegarrd Delta (BD) bitrate and BD-PSNR values

\begin{tabular}{|c|c|c|c|c|}
\hline \multirow{2}{*}{ Sequence } & \multicolumn{2}{|c|}{ BDPSNR(dB) } & \multicolumn{2}{|c|}{ BDBitrate(\%) } \\
\cline { 2 - 5 } & $\begin{array}{c}\text { TZ } \\
\text { vs. } \\
\text { Proposed method }\end{array}$ & $\begin{array}{c}\text { TZHI } \\
\text { vs. } \\
\text { Proposed method }\end{array}$ & $\begin{array}{c}\text { TZ } \\
\text { vs. } \\
\text { Proposed method }\end{array}$ & $\begin{array}{c}\text { TZHI } \\
\text { vs. } \\
\text { Proposed method }\end{array}$ \\
\hline Exit & -0.07 & -0.17 & 5.54 & 6.84 \\
\hline Uli & -0.03 & -0.01 & 0.9 & 0.41 \\
\hline Ballroom & -0.19 & -0.13 & 4.95 & 3.4 \\
\hline Race1 & -0.58 & -0.34 & 14.68 & 8.23 \\
\hline Flamenco2 & -0.15 & -0.07 & 3.34 & 1.51 \\
\hline
\end{tabular}

제안한 기법, $\mathrm{TZ}$ 탐색 기법 그리고 $\mathrm{TZHI}[17]$ 의 평균 PSNR과 BitRate을 Table 2에 나타내었고 BD-PSNR과 $\mathrm{BD}$-BitRate를 Table 3에 제시하였다. 제안한 기법, $\mathrm{TZ}$ 그 리고 TZHI 탐색 기법의 움직임 추정 시간을 Table 4에 나 타내었다. Exit과 Ballroom에서 제안한 기법은 TZ 탐색 기 법보다 움직임 추정의 계산량를 약 $40 \%$ 감소시킨다. 영상
화질은 각각 $0.07(\mathrm{~dB}), 0.19(\mathrm{~dB})$ 저하를 보이고 발생 비트량 은 각각 $5.5 \mathrm{Kbps}, 4.9 \mathrm{Kbps}$ 증가한다. Uli에서 제안한 기법은 $\mathrm{TZ}$ 탐색 기법보다 영상 화질은 약 $0.03(\mathrm{~dB})$ 저하, 비트량은 $0.9 \mathrm{Kbps}$ 증가하지만 움직임 추정 계산량은 약 $66 \%$ 감소시 킴으로 약 2.5배 빠르게 움직임 벡터를 추정할 있 수 있었 다. Race1에서도 영상 화질은 $0.58(\mathrm{~dB})$ 저하, 발생 비트량은 
Table 4. Comparison values of total motion estimation time

\begin{tabular}{|c|c|c|c|c|c|c|c|}
\hline \multirow[t]{2}{*}{ Sequence } & \multirow[t]{2}{*}{$\mathrm{QP}$} & TZHI & $\begin{array}{c}\text { Proposed } \\
\text { method }\end{array}$ & \multirow[t]{2}{*}{$\triangle \mathrm{T}(\%)$} & $\mathrm{TZ}$ & $\begin{array}{l}\text { Proposed } \\
\text { method }\end{array}$ & \multirow[t]{2}{*}{$\triangle \mathrm{T}(\%)$} \\
\hline & & $(\mathrm{sec})$ & $(\mathrm{sec})$ & & $(\mathrm{sec})$ & $(\mathrm{sec})$ & \\
\hline \multirow{4}{*}{ Exit } & 22 & 82615 & 46515 & 0.44 & 77122 & 46515 & 0.40 \\
\hline & 27 & 75471 & 41941 & 0.44 & 69999 & 41941 & 0.40 \\
\hline & 32 & 70484 & 39197 & 0.44 & 64453 & 39197 & 0.39 \\
\hline & 37 & 64855 & 37091 & 0.43 & 60665 & 37091 & 0.39 \\
\hline \multirow{4}{*}{ Uli } & 22 & 204897 & 125769 & 0.39 & 386955 & 125769 & 0.67 \\
\hline & 27 & 188061 & 116867 & 0.38 & 355760 & 116867 & 0.67 \\
\hline & 32 & 177220 & 109849 & 0.38 & 324375 & 109849 & 0.66 \\
\hline & 37 & 160546 & 103575 & 0.35 & 298839 & 103575 & 0.65 \\
\hline \multirow{4}{*}{ Ballroom } & 22 & 88437 & 50848 & 0.43 & 83309 & 50848 & 0.39 \\
\hline & 27 & 82561 & 47492 & 0.42 & 78003 & 47492 & 0.39 \\
\hline & 32 & 78475 & 43932 & 0.44 & 72337 & 43932 & 0.39 \\
\hline & 37 & 73980 & 41188 & 0.44 & 67215 & 41188 & 0.39 \\
\hline \multirow{4}{*}{ Race1 } & 22 & 98219 & 54840 & 0.44 & 215806 & 54840 & 0.75 \\
\hline & 27 & 89408 & 50226 & 0.44 & 199540 & 50226 & 0.75 \\
\hline & 32 & 78869 & 45866 & 0.42 & 176361 & 45866 & 0.74 \\
\hline & 37 & 67291 & 42235 & 0.37 & 154004 & 42235 & 0.73 \\
\hline \multirow{4}{*}{ Flamenco2 } & 22 & 54598 & 28960 & 0.47 & 69597 & 28960 & 0.58 \\
\hline & 27 & 52245 & 27766 & 0.47 & 65944 & 27766 & 0.58 \\
\hline & 32 & 49548 & 26334 & 0.47 & 61253 & 26334 & 0.57 \\
\hline & 37 & 47157 & 24660 & 0.48 & 60091 & 24660 & 0.59 \\
\hline
\end{tabular}

Table 5. Simulation Results : Ballroom (QP 37)

\begin{tabular}{|c|c|c|c|c|c|c|c|c|c|c|c|c|}
\hline sequence & \multicolumn{3}{|c|}{ FS } & \multicolumn{3}{c|}{ TZ } & \multicolumn{3}{c|}{ TZHI } & \multicolumn{3}{|c|}{ Proposed method } \\
\hline Ballroom & $\begin{array}{c}\text { PSNR } \\
(\mathrm{dB})\end{array}$ & $\begin{array}{c}\text { BIT } \\
\text { RATE } \\
\text { (Kbps) }\end{array}$ & $\begin{array}{c}\text { Endocing } \\
\text { time(s) }\end{array}$ & $\begin{array}{c}\text { PSNR } \\
(\mathrm{dB})\end{array}$ & $\begin{array}{c}\text { BIT } \\
\text { RATE } \\
\text { (Kbps) }\end{array}$ & $\begin{array}{c}\text { Endocing } \\
\text { time(s) }\end{array}$ & $\begin{array}{c}\text { PSNR } \\
(\mathrm{dB})\end{array}$ & $\begin{array}{c}\text { BIT } \\
\text { RATE } \\
\text { (Kbps) }\end{array}$ & $\begin{array}{c}\text { Endocing } \\
\text { time(s) }\end{array}$ & $\begin{array}{c}\text { PSNR } \\
\text { (dB) }\end{array}$ & $\begin{array}{c}\text { BIT } \\
\text { RATE } \\
\text { (Kbps) }\end{array}$ & $\begin{array}{c}\text { Endocing } \\
\text { time(s) }\end{array}$ \\
\hline 0 view & 32.11 & 295.15 & 417191 & 32.09 & 296.24 & 7135 & 32.08 & 299.02 & 6965.00 & 32.08 & 300.71 & 4757 \\
\hline 1 view & 31.24 & 156.54 & 434363 & 31.19 & 157.24 & 9622 & 31.14 & 161.89 & 11028.00 & 31.10 & 174.54 & 5405 \\
\hline 2 view & 32.18 & 245.80 & 427006 & 32.15 & 249.14 & 7434 & 32.13 & 250.83 & 7336.00 & 32.11 & 263.90 & 4853 \\
\hline 3 view & 31.24 & 153.23 & 436203 & 31.19 & 153.52 & 9578 & 31.15 & 157.75 & 12114.00 & 31.09 & 171.37 & 5476 \\
\hline 4 view & 31.54 & 268.89 & 428528 & 31.50 & 272.07 & 7578 & 31.47 & 276.25 & 7574.00 & 31.48 & 289.94 & 4954 \\
\hline 5 view & 31.76 & 171.95 & 434723 & 31.68 & 172.13 & 9745 & 31.63 & 176.71 & 11998.00 & 31.56 & 190.93 & 5495 \\
\hline 6 view & 31.89 & 265.47 & 428527 & 31.85 & 267.40 & 7665 & 31.82 & 271.95 & 7676.00 & 31.83 & 283.37 & 4988 \\
\hline 7 view & 31.17 & 244.94 & 430623 & 31.13 & 245.84 & 8458 & 31.09 & 250.87 & 9289.00 & 31.09 & 261.26 & 5260 \\
\hline
\end{tabular}


$14.6 \mathrm{Kbps}$ 증가하였지만 움직임 추정 계산량을 약 $75 \%$ 감소 시킴으로 약 3.2 배 이상 빠르게 움직임 벡터를 추정할 수 있었다. Flamenco2에서 제안한 기법은 $\mathrm{TZ}$ 탐색 기법보다 약 2.5배 정도 빠르게 움직임 벡터를 추정한다.

Exit, Ballroom, Race1, Flamenco2 그리고 Uli에서 제안한 기법은 TZHI 탐색 기법보다 약 2 배 빠르게 움직임 벡터를 추 정한다. Exit, Ballroom, Race1, Flamenco2 그리고 Uli에서 제 안한 기법은 $\mathrm{TZHI}$ 탐색 기법보다 각각 $0.1(\mathrm{~dB}), 0.1(\mathrm{~dB})$, $0.3(\mathrm{~dB}), 0.07(\mathrm{~dB}), 0.01(\mathrm{~dB})$ 화질 저하를 보이고 발생 비트량은 각각 $6.5 \mathrm{Kbps}, 3.5 \mathrm{Kbps}, 8.2 \mathrm{Kbps}, 1.5 \mathrm{Kbps}, 0.4 \mathrm{Kbps}$ 증가한다.

Exit, Ballroom, Race1, Flamenco2 그리고 Uli 영상에서 제안한 기법은 $\mathrm{TZ}$ 탐색 기법과 $\mathrm{TZHI}$ 탐색 기법보다 약 2 3.3배 빠르게 움직임 벡터를 추정하고 비슷한 영상 화질 과 발생 비트량을 보인다.

Ballroom영상에서 $\quad \sim 7 \mathrm{View}$ (QP가 37)에 대해 $\mathrm{FS}$ (Brute force방법), TZ 탐색 기법, TZHI 탐색 기법 그 리고 제안 기법을 이용하여 구해진 PSNR, 발생 비트량 그리고 움직임 벡터 추정에 소요되는 시간을 Table 5에 나타냈다. FS와 TZ 탐색 기법, TZHI 탐색 기법 그리고 제안 기법의 움직임 벡터를 추정하는 시간을 비교한 경 우 $\mathrm{TZ}$ 탐색 기법, TZHI 탐색 기법 그리고 제안 기법은 각각 $98 \%, 97.8 \%, 98.8 \%$ 움직임 추정 계산량을 줄였고 화질은 각각 $0.04(\mathrm{~dB}), 0.07(\mathrm{~dB})$ 그리고 $0.09(\mathrm{Db}$ 화질 저하 를 보였다. 즉, $\mathrm{TZ}$ 탐색 기법, $\mathrm{TZHI}$ 탐색 기법 그리고 제안 기법은 $\mathrm{FS}$ 의 계산량을 약 $98 \%$ 줄이면서 비슷한 화 질을 보였다.

\section{5. 결 론}

본 논문에서는 다시점 비디오의 움직임 추정에 소요되는 계산량을 줄이면서 화질과 발생되는 비트량을 유지하기 위 한 고속 움직임 추정 기법을 제안하였다. 제안한 움직임 추 정 기법은 계층적인 탐색 기법으로 다중 다이아몬드 탐색 패턴, 수정된 다이아몬드 탐색 패턴, 래스터 탐색 패턴들로 이루어져있다. 제안한 움직임 추정기법은 움직임 벡터의 분 포 특성을 이용하여 탐색 점들을 배치하거나 영상 화질에 영향을 미치는 국부적 최소화 문제를 해결하기 위하여 탐색 영역 내에 탐색 점들을 규칙적, 대칭적으로 배치하였다.

본 논문에서 제안한 기법의 성능을 $\mathrm{TZ}$ 탐색 기법과 $\mathrm{TZHI}$ 탐색 기법의 성능과 비교하였을 때 움직임 추정 속도 면에 있어서 약 2 배 3.3 배 향상을 보이고 비슷한 영상 화 질과 발생 비트량을 보인다.

\section{참 고 문 헌}

[1] A. Smolic, K. Mueller, P. Merkle, C. Fehn, P. kauff, P. Eisert and T. Wiegand, "3D Video and Free Viewpoint Video - Technologies, Applications and MPEG Standards," IEEE International Conference on Multimedia and Exposition, July, 2006.
[2] ISO/IEC JTC1/SC29/WG11 N10357, "Vision on 3D Video", Feb., 2009.

[3] T.Koga, K.Iinuma, A.Hirano, Y.Ishiguro, "Motion compensated interframe coding for video conference", NTC81, pp.G5.3.1-5.3.5, 1981.

[4] R.Li, B.Zeng and M.L.Liou, "A New Three Step Search Algorithm for Block Motion Estimation," IEEE Trans. on Circuits and System for Video Technology Vol.4, No.4, pp.438-441, Aug., 1994.

[5] J.R.Jain and A.K.Jain, "Displacement measurement and its application in Interframe image Coding," IEEE Trans. on Communications, Vol.29, No.12, pp.1779-1808, 1981.

[6] L.M.Po and W.C.Ma, "A Novel Four Search Algorithm for Block Motion Estimation," IEEE Transactions on Circuit and Systems for Video Technology Vol.6. pp.313-317, 1996.

[7] J.Y. Tham, S.Ranganath and A.A.Kassim, "A Novel Unretricted Center-Biased Diamond Search Algorithm for Block Motion Estimation," IEEE Transactions on Circuits and Systems for Video Technology. Vol.8, pp.369-377, 1998.

[8] S.Zhu and K.K.Ma "A New Diamond Search Algorithm for Fast Block Matching Motion”, IEEE Transaction on Image Processing Vol.9, No.2, pp.287-290, 2000.

[9] Yuk Ying Chung ,Neil W.Bergmann "Fast Search Block Matching Motion Estimation Algorithm using FPGA," Visual Communications and Image Processing 2000. Proc.SPIE Vol.4067, pp.913-921.

[10] Danian Gong, Yun He, "Fast Motion Estimation Algorithm using Horizontal and Multi-grid Search Strategy," Picture Coding Symposium 2001. pp.362- 365.

[11] Prabhudev Irappa Howur, K. K. Ma, "Report on Performance of Fast Motion Estimation using Motion Vector Field Adaptive Search Technique," ISO/IEC/JCTI/SC29/WG11 M5453, Dec., 1999.

[12] Ce Zhu, Xion Lin and Lau-Pui Chau, "Hexagon based search pattern for fast block motion estimation,"IEEE Transactions on Circuits and Systems for Video Technology. Vol.12, pp.349-355, 2002.

[13] A. M. Tourapis, O. C. Au, M. L. Liou, "Fast Block Matching Motion Estimation using Predictive Motion Vector Field Adaptive Search Technique," ISO/IEC/JCTI/SC29/WG11 MPEG2000/M5866, Mar., 2000.

[14] Z. Chen, P. Zhou, Y. He, "Fast Integer pel and Fractional pel motion estimation in for JVT" in JVT of ISO/ICE/ MPEG and ITU-T VCEG, 6th meeting, 2002.

[15] TANG Xiu-lil, OAT Sheng-kui CAT Can-hui, "An Analysis of TZSearch Algorithm in JMVC,” pp.516-519, 2010.

[16] H. S Yoon, G.S Lee, "Adaptive Motion Estimation method using temporal correlation,” The KIPS Transactions: Part B, Vol.9, No.2, pp.199-204, 2004.

[17] N.Purnachand, Luis Nero Alves, Antonio Navarro, "Improvements to $\mathrm{TZ}$ search motion estimation algorithm for multiview video coding," IWSSIP 2012, pp.388-391, 2012. 


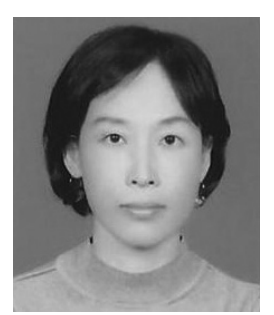

\section{윤 효 순}

e-mail : estheryoon@hotmail.com

2000년 3월 2002년 2월 전남대학교 전산학과(이학석사)

2002년 3월 2005년 2월 전남대학교 전산학과(이학박사)

관심분야: 영상처리, 영상부호화, 멀티

미디어 시스템, 다시점 부호화

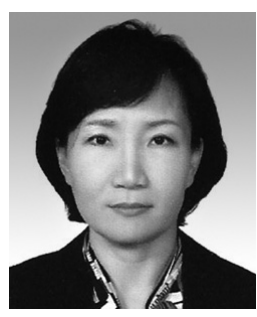

김 미 영

e-mail :kimmee@dorip.ac.kr

1994년 3월 1997년 8월 전남대학교 전산학과(이학박사)

1998년 3월 현 재 전남도립대학교 보건의료과 교수

관심분야: 영상처리, 영상부호화, 멀티미디어 시스템 